\title{
Optimal Ordering Policy for Deteriorating Items with Limited Storage Capacity under Two-Level Trade Credit Linked to Order Quantity by a Discounted Cash-Flow Analysis
}

\author{
Hui-Ling Yang \\ Department of Computer Science and Information Engineering, Hungkuang University, Taiwan \\ Email: hui@sunrise.hk.edu.tw
}

How to cite this paper: Yang, H.-L. (2019) Optimal Ordering Policy for Deteriorating Items with Limited Storage Capacity under Two-Level Trade Credit Linked to Order Quantity by a Discounted Cash-Flow Analysis. Open Journal of Business and Management, 7, 919-940.

https://doi.org/10.4236/ojbm.2019.72063

Received: March 19, 2019

Accepted: April 21, 2019

Published: April 24, 2019

Copyright $\odot 2019$ by author(s) and Scientific Research Publishing Inc. This work is licensed under the Creative Commons Attribution International License (CC BY 4.0).

http://creativecommons.org/licenses/by/4.0/

\begin{abstract}
Nowadays, the supplier often provides cash discount or permissible delay in payments to its retailers, if the order quantity attains a certain amount. Likewise, the retailer also provides a downstream trade credit period to his customers. In practice, as the supplier provides price discounts for bulk purchases, the retailer may purchase more goods than can be stored in its owned warehouse and store the excess quantities in a rented warehouse. Thus, a two-warehouse inventory model is needed to be considered. Further, the cost is usually affected by the present value of time and products deteriorate as time increases. Therefore, this paper develops a supplier-retailer-customer chain inventory model in which 1) two-level trade credit linked to order quantity is considered; 2) storage capacity is limited; 3) the effect of inflation and time value of money by a discounted cash-flow analysis is taken into account. The demand rate is linearly increasing with time and the deterioration rate is constant. Based on the viewpoint of cost minimization, the objective is to find the optimal replenishment cycle and order quantity to keep the present value of the total relevant cost per unit time as minimum as possible. The research shows that in each case discussed, the optimal solution for each case exists uniquely. Finally, numerical examples are provided for illustration and some managerial insights based on the numerical results are also presented.
\end{abstract}

\section{Keywords}

Deterioration, Storage Capacity, Trade Credit, Order Quantity, Discounted Cash Flow 


\section{Introduction}

In the classical EOQ model, the supplier often prefers to offer his customers a delay period for payment to attract new customers and promote more sales, especially in the present of economic depression circumstances. Usually, there is no interest charge if the outstanding amount is paid within this permissible delay period. However, if the payment is unpaid in full by the end of the permissible delay period, interest is charged on the outstanding amount. On the other hand, the policy of granting credit terms adds an additional cost to the supplier as well as an additional dimension of default risk. The literature reviews are described as the following subsections.

\subsection{Papers Related with Permissible Delay in Payment or Two-Level Trade Credit}

Goyal [1] developed an EOQ model under the conditions of a permissible delay in payments, and ignored the difference between the selling price and the purchase cost. Shah [2] considered a stochastic inventory model when delays in payments are permissible. Aggarwal and Jaggi [3] extended Goyal's model to consider the deteriorating items. Jamal et al. [4] further generalized Aggarwal and Jaggi's model to allow for shortages. Concurrently, Hwang and Shinn [5] added the pricing strategy to the model, and developed the optimal price and lot-sizing for a retailer under the condition of a permissible delay in payments. Chang and Dye [6] proposed an inventory model for Weibull distribution deteriorating items with partial backlogging and permissible delay in payments. Teng et al. [7] provided an economic order quantity model with trade credit financing for non-decreasing demand. Other related research articles can be found in Teng [8], Teng et al. [9], Hsieh et al. [10] and their references.

The aforementioned models assumed that the supplier offers the retailer a permissible delay period in payment (i.e., an upstream trade credit). Sometimes, the retailers also do such a way to their customers (i.e., a downstream trade credit). It is a so-called two-level trade credit policy. Huang [11] proposed an optimal retailer's ordering policies in the EOQ model under trade credit financing. Ouyang et al. [12] proposed an EOQ model for deteriorating items under trade credit. Teng and Goyal [13] provided an optimal ordering policy for a retailer in a supply chain with up-stream and down-stream trade credits. Min et al. [14] proposed an inventory model for deteriorating items under stock-dependent demand and two-level trade credit. Lately, Rameswari and Uthayakumar [15] provided an integrated inventory model for deteriorating items with price-dependent demand under two-level trade credit policy.

\subsection{Papers Related with Permissible Delay in Payment or Two-Level Trade Credit Linked to Order Quantity}

In practice, the supplier is more willing to provide a delay payment period for his retailers as they order the quantity larger than predetermined quantity. Chang 
et al. [16] developed an EOQ model for deteriorating items under supplier credits linked to ordering quantity. Chung and Liao [17] provided lot-sizing decisions under trade credit depending on the ordering quantity. Jaggi et al. [18] proposed retailer's optimal replenishment decisions with credit-linked demand under permissible delay in payments.

In order to encourage more sales, the supplier often offers the retailer with conditional permissible delay period as the retailer orders more than a predetermined quantity. Kreng and Tan [19] proposed an inventory model under two levels of trade credit depending on the order quantity. Teng et al. [20] provided an inventory model for deteriorating demand under two levels of trade credit linked to order quantity. Recently, Sash and Cárdenas-Barrón [21] provided an inventory model which is a retailer's decision for ordering and credit policies with deteriorating items when a supplier offers order-linked credit or cash discount. Ting [22] gives some comments on the EOQ model for deteriorating items with conditional trade credit linked to order quantity. Many related research articles can be found in their references.

\subsection{Papers Related with Trade Credit and Limited Storage Capacity or Discounted Cash Flow Analysis}

As the suppliers provide price discounts for bulk purchases, the retailer may purchase more goods than can be stored in its owned warehouse and store the excess quantities in a rented warehouse. Chung and Huang [23] proposed the inventory model for deteriorating items with limited storage capacity under permissible delay in payments. Huang [24] proposed an inventory model under two levels of trade credit and limited storage space without derivatives. Chung and Huang [25] provided an optimal retailer's ordering policies for deteriorating items with limited storage capacity under trade credit financing. Ouyang et al. [26] proposed an EOQ model with limited storage capacity under trade credits.. Recently, Lin et al. [27] provided an integrated inventory model for two-stage deterioration under trade credit and variable capacity utilization.

In reality, due to today's competitive markets, the relevant costs involved in the inventory model are affected by the effect of inflation and time value of money. Thus, to consider not only the opportunity loss (i.e., time value of money) of trade credit, but also on all relevant costs is necessary. Chen and Teng [28] provided an inventory and credit decisions for time-varying deteriorating items with up-stream and down-stream trade credit financing by discounted cash flow analysis. Wu et al. [29] proposed inventory models for deteriorating items with maximum lifetime under downstream partial trade credit to credit-risk customers by discounted cash-flow analysis. Li et al. [30] provided a pricing and lot-sizing policies for perishable products with advance-cash-credit payments by a discounted cash-flow analysis.

Therefore, this paper extends the aforementioned model to develop a supplier-retailer-customer chain inventory model in which 1) two-level trade credit linked to order quantity is considered 2) storage capacity is limited 3) the effect 
of inflation and time value of money by a discounted cash-flow analysis is incorporated. The demand rate is linearly increasing with time and the deterioration rate is constant. If the order quantity exceeds the predetermined quantity or the capacity of own-warehouse, then an upstream trade credit period is permitted or it is necessary to rent a warehouse to store the excessive items. That is, a generalized deteriorating inventory model with limited storage capacity under two levels of trade credit linked to order quantity and by a discounted cash-flow analysis is considered. As a result, this paper is a general framework that includes numerous previous models as special cases, such as Chang et al. [16], Chung and Liao [17], Teng et al. [20] and others. Based on the viewpoint of cost minimization, the objective is to find the optimal replenishment cycle and order quantity to keep the present value of the total relevant cost per unit time as minimum as possible. Numerical examples are provided for illustration and some managerial insights are presented.

The remainder of the paper is structured as follows. Section 2 introduces the assumptions and notation needed to develop the proposed inventory model. Section 3 formulates the model. Section 4 discusses some theoretical results and provides an algorithm to find the optimal solutions. Section 5 provides numerical examples to illustrate the proposed model. Section 6 concludes the results and presents some managerial insights. Further, provides some future research directions.

\section{Assumptions and Notation}

In this research, the mathematical models proposed are based on the following assumptions:

1) Lead time is zero and replenishment is instantaneous.

2) Shortages are not allowed.

3) The own warehouse has a limited capacity $W$ and the rented warehouse has unlimited capacity.

4) A constant fraction of the on-hand inventory deteriorates per unit of time and there is no repair or replacement of the deteriorated inventory (i.e., the salvage value of a deteriorating item is zero). Without loss of generality, assuming that the deterioration rate in both own warehouse (OW) and rented warehouse (RW) is the same.

5) If the order quantity is larger than the capacity of own warehouse, then the retailer will rent a warehouse to store the excessive items. For economic reasons, the goods of RW are consumed and cleared before OW.

6) The inventory costs (including holding cost and deterioration cost) in RW are higher than those in OW.

7) If the order quantity is larger than the predetermined order quantity, then the delay in payment offered by supplier is permitted, otherwise, the retailer must pay immediately as the items received.

8) The retailer also provides a downstream trade credit period to his customers.

9) If the replenishment cycle is less than the permissible delay period, then the 
retailer needs not to pay any interest charged by the supplier. If not, the retailer needs to pay the interest charged on the items in stock to the supplier.

10) The retailer can accumulate revenue and earn interest after his customers pay for the amount until the end of the trade credit period offered by the supplier.

In addition, the following notation is used throughout this paper.

$f(t)=$ the demand rate at time $t$, we here assume that $f(t)$ is linear time dependent, i.e., $f(t)=a+b t$.

$W=$ the capacity of owned warehouse (OW).

$Q=$ the order quantity.

$Q_{d}=$ the predetermined order quantity at which the delay is permitted by the supplier.

$T_{d}=$ the time interval that $Q_{d}$ units are depleted to zero due to both demand and deterioration.

$T_{a}=$ the time at which the inventory level reaches $W$ units due to both demand and deterioration where $T_{a}\left\{\begin{array}{ll}=0, & \text { if } Q \leq W \\ >0, & \text { if } Q>W\end{array}\right.$.

$T_{w}=$ the time interval that $W$ units are depleted to zero due to both demand and deterioration.

$M=$ the retailer's trade credit period offered by supplier in years.

$N=$ the customer's trade credit period offered by retailer in years.

$T=$ the length of replenishment cycle in years, where $T=T_{a}+T_{w}$.

$r=$ the annual interest rate per year.

$\theta=$ the deterioration rate, where $0<\theta<1$.

$A=$ the replenishment cost per order.

$h=$ the holding cost per unit per unit time in OW excluding interest charge.

$k=$ the holding cost per unit per unit time in RW excluding interest charge.

From Assumption 5, we have $k>h$.

$c=$ the unit purchasing cost.

$I_{e}=$ the interest earned per dollar per unit time per year by the retailer.

$I_{p}=$ the interest paid per dollar per unit time per year by the retailer.

$I(t)=$ the inventory level at time $t$.

$T C_{i j}(T)=$ the present value of the annual total relevant cost per unit time, which is a function of $T$, where $i=1,2,3,4, j=1,2$.

$T^{*}=$ the optimal replenishment cycle time of $T C_{i j}(T), i=1,2,3,4$, $j=1,2$.

$Q^{*}=$ the optimal order quantity.

\section{Research Models}

For the model, the inventory depletes due to the combined effect of demand and deterioration. The inventory level at time $t$ is governed by the following differential equations:

$$
\frac{\mathrm{d} I(t)}{\mathrm{d} t}=-f(t)-\theta I(t), \quad 0 \leq t \leq T
$$


with the boundary condition $I(T)=0$ The solutions to (1) is

$$
I(t)=\mathrm{e}^{-\theta t} \int_{t}^{T} \mathrm{e}^{\theta u} f(u) \mathrm{d} u, \quad 0 \leq t \leq T
$$

Thus, the order quantity for each cycle is

$$
Q=I(0)=\int_{0}^{T} \mathrm{e}^{\theta t} f(t) \mathrm{d} t .
$$

From Equation (3), we can obtain the time interval $T_{d}, T_{a}$ and $T_{w}$ by using the following equations:

$$
\begin{gathered}
Q_{d}=\int_{0}^{T_{d}} \mathrm{e}^{\theta t} f(t) \mathrm{d} t \\
W=\int_{T_{a}}^{T} \mathrm{e}^{\theta t} f(t) \mathrm{d} t
\end{gathered}
$$

and

$$
Q-W=\int_{0}^{T_{a}} \mathrm{e}^{\theta t} f(t) \mathrm{d} t, \quad \text { if } Q>W
$$

respectively. Therefore, the profit of the inventory system consists of the following components.

1) The ordering cost is $A$.

2) If $Q \leq W$, then the inventory holding cost in RW and OW are

$$
C_{H R}=0 \text {, }
$$

and

$$
C_{H O}=h \int_{0}^{T} \mathrm{e}^{-r t} I(t) \mathrm{d} t=h \int_{0}^{T} \mathrm{e}^{-(\theta+r) t} \int_{t}^{T} \mathrm{e}^{\theta u} f(u) \mathrm{d} u \mathrm{~d} t .
$$

If $Q>W$, then the inventory holding cost in RW and OW are

$$
C_{H R}=k \int_{0}^{T_{a}} \mathrm{e}^{-r t}[I(t)-W] \mathrm{d} t=k\left[\int_{0}^{T_{a}} \mathrm{e}^{-(\theta+r) t} \int_{t}^{T_{a}} \mathrm{e}^{\theta u} f(u) \mathrm{d} u \mathrm{~d} t-W \int_{0}^{T_{a}} \mathrm{e}^{-r t} \mathrm{~d} t\right]
$$

and

$$
C_{H O}=h\left[\int_{0}^{T_{a}} W \mathrm{e}^{-(\theta+r) t} \mathrm{~d} t+\int_{T_{a}}^{T} \mathrm{e}^{-(\theta+r) t} \int_{t}^{T} \mathrm{e}^{\theta u} f(u) \mathrm{d} u \mathrm{~d} t\right] .
$$

3) The deteriorating cost is $C_{d}=\theta c \int_{0}^{T} \mathrm{e}^{-r t} I(t) \mathrm{d} t$.

The graphical representation of the inventory model, if $Q>W$ is shown in Figure 1.

\section{1. $Q<Q_{d}$}

In this case, the retailer's order quantity is less than $Q_{d}$. Hence, the permissible delay in payment is not allowed (i.e., $M=0$ ). Meanwhile, the retailer offers a permissible delay of $N$ to its buyers. Consequently, the retailer must fiancé all items ordered at time 0 , and start to payoff the loan after time $N$. For details, please see Figure 2. Thus, the interest paid by the retailer is

$$
\begin{aligned}
& c I_{p}\left[\int_{0}^{N} \mathrm{e}^{-r t} I(0) \mathrm{d} t+\int_{N}^{T+N} \mathrm{e}^{-r(t-N)} I(t-N) \mathrm{d} t\right] \\
& =c I_{p}\left[\int_{0}^{N} \mathrm{e}^{-r t} \int_{0}^{T} \mathrm{e}^{\theta u} f(u) \mathrm{d} u \mathrm{~d} t+\int_{N}^{T+N} \mathrm{e}^{-(\theta+r)(t-N)} \int_{t-N}^{T} \mathrm{e}^{\theta u} f(u) \mathrm{d} u \mathrm{~d} t\right]
\end{aligned}
$$




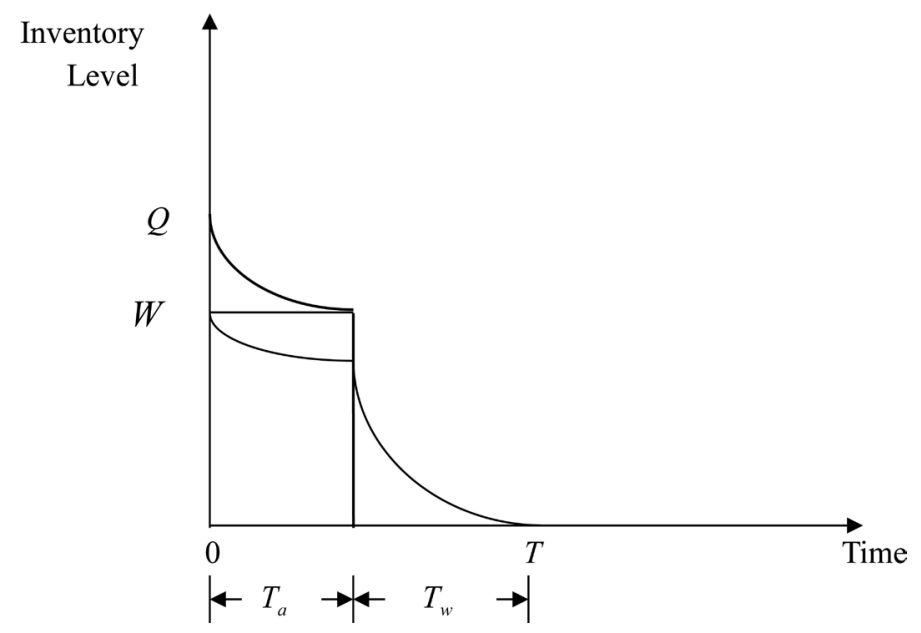

Figure 1. Graphical representation of the inventory Model, if $Q>W$.

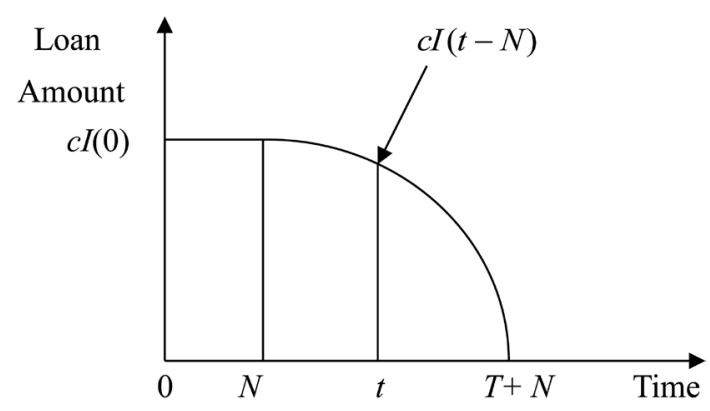

Figure 2. Graphical representation for $T<T_{d}$.

Based on whether the order quantity is larger than the capacity of own warehouse or not, there are two sub-case: i) $Q \leq W$ ii) $Q>W$.

Hence, the present value of the retailer's annual total relevant cost per unit time is

$$
\begin{aligned}
T C_{11}(T)= & \left\{A+(h+\theta c) \int_{0}^{T} \mathrm{e}^{-(\theta+r) t} \int_{t}^{T} \mathrm{e}^{\theta u} f(u) \mathrm{d} u \mathrm{~d} t\right. \\
& +c I_{p}\left[\int_{0}^{N} \mathrm{e}^{-r t} \int_{0}^{T} \mathrm{e}^{\theta u} f(u) \mathrm{d} u \mathrm{~d} t\right. \\
& \left.\left.+\int_{N}^{T+N} \mathrm{e}^{-(\theta+r)(t-N)} \int_{t-N}^{T} \mathrm{e}^{\theta u} f(u) \mathrm{d} u \mathrm{~d} t\right]\right\} / T, \quad \text { if } Q \leq W \\
T C_{12}(T)= & \left\{A+\theta c \int_{0}^{T} \mathrm{e}^{-(\theta+r) t} \int_{t}^{T} \mathrm{e}^{\theta u} f(u) \mathrm{d} u \mathrm{~d} t\right. \\
& +h\left[\int_{0}^{T_{a}} W \mathrm{e}^{-(\theta+r) t} \mathrm{~d} t+\int_{T_{a}}^{T} \mathrm{e}^{-(\theta+r) t} \int_{t}^{T} \mathrm{e}^{\theta u} f(u) \mathrm{d} u \mathrm{~d} t\right] \\
& +k\left[\int_{0}^{T_{a}} \mathrm{e}^{-(\theta+r) t} \int_{t}^{T_{a}} \mathrm{e}^{\theta u} f(u) \mathrm{d} u \mathrm{~d} t-W \int_{0}^{T_{a}} \mathrm{e}^{-r t} \mathrm{~d} t\right] \\
& +c I_{p}\left[\int_{0}^{N} \mathrm{e}^{-r t} \int_{0}^{T} \mathrm{e}^{\theta u} f(u) \mathrm{d} u \mathrm{~d} t\right. \\
& \left.\left.+\int_{N}^{T+N} \mathrm{e}^{-(\theta+r)(t-N)} \int_{t-N}^{T} \mathrm{e}^{\theta u} f(u) \mathrm{d} u \mathrm{~d} t\right]\right\} / T, \quad \text { if } Q>W
\end{aligned}
$$

\section{2. $Q \geq Q_{d}$}

In this case, based on the supplier's trade credit $M$, and the last customer's pay- 
ment time $T+N$, the retailer has three possible choices on its replenishment cycle time $T:$ 1) $0<M<N$ 2) $0<N \leq M$ and $M \leq T+N$ 3) $0<N \leq M$ and $M>T+N$.

\subsubsection{The Case of $0<M<N$}

Since $M<N$, there is no interest earned for the retailer. In addition, the retailer has to finance all items ordered after time $M$ at an interest charged $I_{p}$ per dollar per year, and start to payoff the loan after time $N$ as shown in Figure 3. Consequently, the interest charged is given by

$$
\begin{aligned}
& c I_{p}\left[\int_{M}^{N} \mathrm{e}^{-r(t-M)} I(0) \mathrm{d} t+\int_{N}^{T+N} \mathrm{e}^{-r(t-N)} I(t-N) \mathrm{d} t\right] \\
& =c I_{p}\left[\int_{M}^{N} \mathrm{e}^{-r(t-M)} \int_{0}^{T} \mathrm{e}^{\theta u} f(u) \mathrm{d} u \mathrm{~d} t+\int_{N}^{T+N} \mathrm{e}^{-(\theta+r)(t-N)} \int_{t-N}^{T} \mathrm{e}^{\theta u} f(u) \mathrm{d} u \mathrm{~d} t\right]
\end{aligned}
$$

In the same way, based on whether the order quantity is larger than the capacity of own warehouse or not, there are two sub-case: i) $Q \leq W$ ii) $Q>W$.

Hence, the present value of the retailer's annual total relevant cost per unit time is

$$
\begin{aligned}
T C_{21}(T)= & \left\{A+(h+\theta c) \int_{0}^{T} \mathrm{e}^{-(\theta+r) t} \int_{t}^{T} \mathrm{e}^{\theta u} f(u) \mathrm{d} u \mathrm{~d} t\right. \\
& +c I_{p}\left[\int_{M}^{N} \mathrm{e}^{-r(t-M)} \int_{0}^{T} \mathrm{e}^{\theta u} f(u) \mathrm{d} u \mathrm{~d} t\right. \\
& \left.\left.+\int_{N}^{T+N} \mathrm{e}^{-(\theta+r)(t-N)} \int_{t-N}^{T} \mathrm{e}^{\theta u} f(u) \mathrm{d} u \mathrm{~d} t\right]\right\} / T, \text { if } Q \leq W \\
T C_{22}(T)= & \left\{A+\theta c \int_{0}^{T} \mathrm{e}^{-(\theta+r) t} \int_{t}^{T} \mathrm{e}^{\theta u} f(u) \mathrm{d} u \mathrm{~d} t\right. \\
& +h\left[\int_{0}^{T_{a}} W \mathrm{e}^{-(\theta+r) t} \mathrm{~d} t+\int_{T_{a}}^{T} \mathrm{e}^{-(\theta+r) t} \int_{t}^{T} \mathrm{e}^{\theta u} f(u) \mathrm{d} u \mathrm{~d} t\right] \\
& +k\left[\int_{0}^{T_{a}} \mathrm{e}^{-(\theta+r) t} \int_{t}^{T} \mathrm{e}^{\theta_{u}} f(u) \mathrm{d} u \mathrm{~d} t-W \int_{0}^{T_{a}} \mathrm{e}^{-r t} \mathrm{~d} t\right] \\
& +c I_{p}\left[\int_{M}^{N} \mathrm{e}^{-r(t-M)} \int_{0}^{T} \mathrm{e}^{\theta u} f(u) \mathrm{d} u \mathrm{~d} t\right. \\
& \left.\left.+\int_{N}^{T+N} \mathrm{e}^{-(\theta+r)(t-N)} \int_{t-N}^{T} \mathrm{e}^{\theta u} f(u) \mathrm{d} u \mathrm{~d} t\right]\right\} / T, \text { if } Q>W
\end{aligned}
$$

Note that Equations (10) and (11) are special cases of Equations (13) and (14) in which $M=0$.

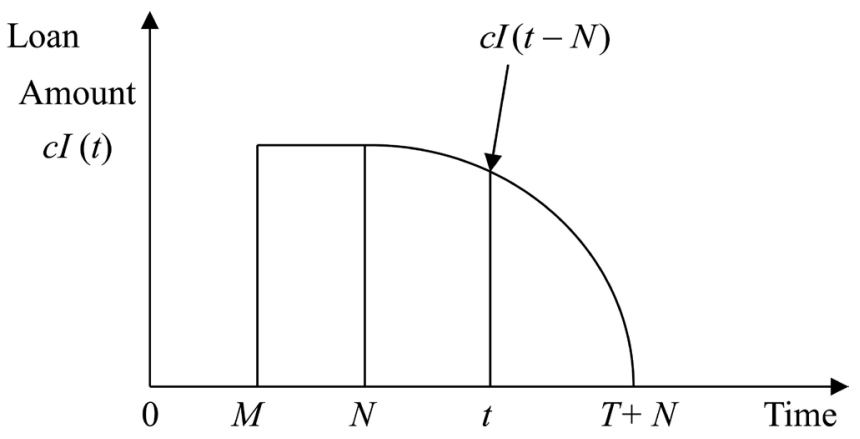

Figure 3. Graphical representation for $T \geq T_{d}$ and $M<N$. 


\subsubsection{The Case of $0<N \leq M$ and $M \leq T+N$}

When $M \leq T+N$, the retailer cannot receive the last payment before the permissible delay time $M$. As a result, the retailer must finance all items sold after time $(M-N)$ at time $M$, and pay off the loan until $T+N$ at an interest rate of $I_{p}$ per dollar per year as shown in Figure 4. Therefore, the interest paid is given by

$$
c I_{p} \int_{M}^{T+N} \mathrm{e}^{-r(t-M)} I(t-M) \mathrm{d} t=c I_{p} \int_{M}^{T+N} \mathrm{e}^{-(\theta+r)(t-M)} \int_{t-M}^{T} \mathrm{e}^{\theta u} f(u) \mathrm{d} u \mathrm{~d} t .
$$

On the other hand, the retailer starts selling products at time 0 , and receiving the money at time $N$. Consequently, the retailer accumulates sales revenue in an account that earns $I_{e}$ per dollar per year starting from $N$ through $M$ as shown in Figure 4. Therefore, the interest earned is given by

$$
p I_{e} \int_{N}^{M} \mathrm{e}^{-r(t-N)} \int_{N}^{t} f(u-N) \mathrm{d} u \mathrm{~d} t .
$$

Likewise, based on whether the order quantity is larger than the capacity of own warehouse or not, there are two sub-case: i) $Q \leq W$ ii) $Q>W$.

As a result, the present value of the retailer's annual total relevant cost per unit time is

$$
\begin{aligned}
T C_{31}(T)= & \left\{A+(h+\theta c) \int_{0}^{T} \mathrm{e}^{-(\theta+r) t} \int_{t}^{T} \mathrm{e}^{\theta u} f(u) \mathrm{d} u \mathrm{~d} t\right. \\
& +c I_{p} \int_{M}^{T+N} \mathrm{e}^{-(\theta+r)(t-M)} \int_{t-M}^{T} \mathrm{e}^{\theta u} f(u) \mathrm{d} u \mathrm{~d} t \\
& \left.-p I_{e} \int_{N}^{M} \mathrm{e}^{-r(t-N)} \int_{N}^{t} f(u-N) \mathrm{d} u \mathrm{~d} t\right\} / T, \quad \text { if } Q \leq W \\
T C_{32}(T)= & \left\{A+\theta c \int_{0}^{T} \mathrm{e}^{-(\theta+r) t} \int_{t}^{T} \mathrm{e}^{\theta u} f(u) \mathrm{d} u \mathrm{~d} t\right. \\
& +h\left[\int_{0}^{T_{a}} W \mathrm{e}^{-(\theta+r) t} \mathrm{~d} t+\int_{T_{a}}^{T} \mathrm{e}^{-(\theta+r) t} \int_{t}^{T} \mathrm{e}^{\theta u} f(u) \mathrm{d} u \mathrm{~d} t\right] \\
& +k\left[\int_{0}^{T_{a}} \mathrm{e}^{-(\theta+r) t} \int_{t}^{T_{a}} \mathrm{e}^{\theta u} f(u) \mathrm{d} u \mathrm{~d} t-W \int_{0}^{T_{a}} \mathrm{e}^{-r t} \mathrm{~d} t\right] \\
& +c I_{p} \int_{M}^{T+N} \mathrm{e}^{-(\theta+r)(t-M)} \int_{t-M}^{T} \mathrm{e}^{\theta u} f(u) \mathrm{d} u \mathrm{~d} t \\
& \left.-p I_{e} \int_{N}^{M} \mathrm{e}^{-r(t-N)} \int_{N}^{t} f(u-N) \mathrm{d} u \mathrm{~d} t\right\} / T, \quad \text { if } Q>W
\end{aligned}
$$

\subsubsection{The Case of $0<N \leq M$ and $M>T+N$}

Since the order quantity is larger than or equal to $Q_{d}$, the retailer receives the

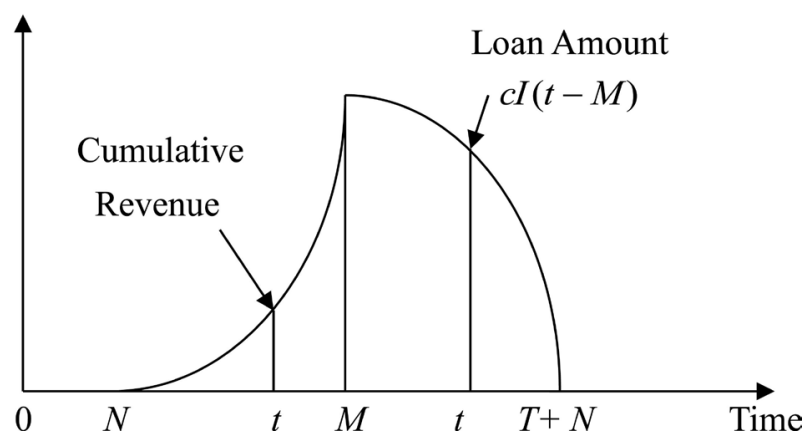

Figure 4. Graphical representation for $T \geq T_{d}, \quad 0<N \leq M$ and $M \leq T+N$. 
permissible delay in payment. If $M>T+N$, then the retailer receives all payments from its customers by the time $T+N$ which is before the permissible delay time $M$. Hence, the retailer has the money to pay the supplier at time $M$, and does not have the interest charges. In the meantime, the retailer receives the revenue and deposits into a bank to earn interest as shown in Figure 5. The interest earned by the retailer is

$$
p I_{e}\left[\int_{N}^{T+N} \mathrm{e}^{-r(t-N)} \int_{N}^{t} f(u-N) \mathrm{d} u \mathrm{~d} t+\int_{T+N}^{M} \mathrm{e}^{-r(t-T-N)} \int_{0}^{T} f(u) \mathrm{d} u \mathrm{~d} t\right] .
$$

Similarly, based on whether the order quantity is larger than the capacity of own warehouse or not, there are two sub-case: i) $Q \leq W$ ii) $Q>W$.

Therefore, the present value of the retailer's annual total relevant cost per unit time is

$$
\begin{aligned}
T C_{41}(T)= & \left\{A+(h+\theta c) \int_{0}^{T} \mathrm{e}^{-(\theta+r) t} \int_{t}^{T} \mathrm{e}^{\theta u} f(u) \mathrm{d} u \mathrm{~d} t\right. \\
& -p I_{e}\left[\int_{N}^{T+N} \mathrm{e}^{-r(t-N)} \int_{N}^{t} f(u-N) \mathrm{d} u \mathrm{~d} t\right. \\
& \left.\left.+\int_{T+N}^{M} \mathrm{e}^{-r(t-T-N)} \int_{0}^{T} f(u) \mathrm{d} u \mathrm{~d} t\right]\right\} / T, \quad \text { if } Q \leq W \\
T C_{42}(T)= & \left\{A+\theta c \int_{0}^{T} \mathrm{e}^{-(\theta+r) t} \int_{t}^{T} \mathrm{e}^{\theta u} f(u) \mathrm{d} u \mathrm{~d} t\right. \\
& +h\left[\int_{0}^{T_{a}} W \mathrm{e}^{-(\theta+r) t} \mathrm{~d} t+\int_{T_{a}}^{T} \mathrm{e}^{-(\theta+r) t} \int_{t}^{T} \mathrm{e}^{\theta u} f(u) \mathrm{d} u \mathrm{~d} t\right] \\
& +k\left[\int_{0}^{T_{a}} \mathrm{e}^{-(\theta+r) t} \int_{t}^{T_{a}} \mathrm{e}^{\theta u} f(u) \mathrm{d} u \mathrm{~d} t-W \int_{0}^{T_{a}} \mathrm{e}^{-r t} \mathrm{~d} t\right] \\
& -p I_{e}\left[\int_{N}^{T+N} \mathrm{e}^{-r(t-N)} \int_{N}^{t} f(u-N) \mathrm{d} u \mathrm{~d} t\right. \\
& \left.\left.+\int_{T+N}^{M} \mathrm{e}^{-r(t-T-N)} \int_{0}^{T} f(u) \mathrm{d} u \mathrm{~d} t\right]\right\} / T, \quad \text { if } Q>W
\end{aligned}
$$

\section{Theoretical Results}

In order to find the optimal solution of each case, we derive the theoretical results in the following two ways: i) $Q \leq W$ ii) $Q>W$.

\subsection{The Case of Order Quantity Is Not Greater than the Capacity of Own-Warehouse (i.e., $Q \leq W$ )}

In this sub-section, we discuss each case shown in Section 3 as the order quantity

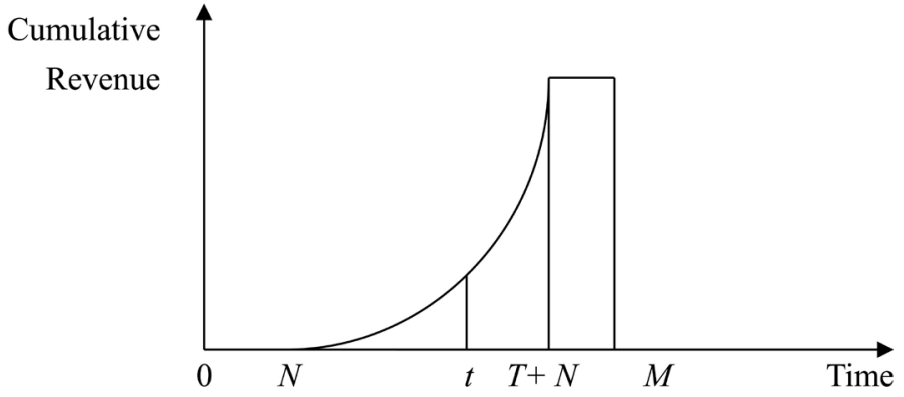

Figure 5. Graphical representation for $T \geq T_{d}, 0<N \leq M$ and $M>T+N$. 
is not greater than the capacity of own-warehouse. To minimize the present value of the total relevant cost, it is necessary to calculate the first and second order derivatives of $T C_{i 1}(T), i=1,2,3,4$, with respect to $T$, and let $\mathrm{d} T C_{i 1}(T) / \mathrm{d} T=0$. We have the following results.

$$
\begin{aligned}
& \frac{\mathrm{d} T C_{11}}{\mathrm{~d} T}=\left\{\mathrm { e } ^ { \theta T } ( a + b T ) \left[\left(h+\theta c+c I_{p}\right)\left(\frac{1-\mathrm{e}^{-(\theta+r) T}}{\theta+r}\right)\right.\right. \\
& \left.\left.+c I_{p}\left(\frac{1-\mathrm{e}^{-r N}}{r}\right)\right]-T C_{11}\right\} / T=0 \\
& \left.\frac{\mathrm{d}^{2} T C_{11}}{\mathrm{~d} T^{2}}\right|_{\frac{\mathrm{d} T C_{11}}{\mathrm{~d} T}=0} \\
& =\left\{\mathrm { e } ^ { \theta T } [ \theta ( a + b T ) + b ] \left[\left(h+\theta c+c I_{p}\right)\left(\frac{1-\mathrm{e}^{-(\theta+r) T}}{\theta+r}\right)\right.\right. \\
& \left.\left.+c I_{p}\left(\frac{1-\mathrm{e}^{-r N}}{r}\right)\right]+\mathrm{e}^{\theta T}(a+b T)\left(h+\theta c+c I_{p}\right) \mathrm{e}^{-(\theta+r) T}\right\} / T>0 \\
& \frac{\mathrm{d} T C_{21}}{\mathrm{~d} T}=\left\{\mathrm { e } ^ { \theta T } ( a + b T ) \left[\left(h+\theta c+c I_{p}\right)\left(\frac{1-\mathrm{e}^{-(\theta+r) T}}{\theta+r}\right)\right.\right. \\
& \left.\left.+c I_{p}\left(\frac{1-\mathrm{e}^{-r(N-M)}}{r}\right)\right]-T C_{21}\right\} / T=0 \\
& \left.\frac{\mathrm{d}^{2} T C_{21}}{\mathrm{~d} T^{2}}\right|_{\frac{\mathrm{d} T C_{21}}{\mathrm{~d} T}=0} \\
& =\left\{\mathrm { e } ^ { \theta T } [ \theta ( a + b T ) + b ] \left[\left(h+\theta c+c I_{p}\right)\left(\frac{1-\mathrm{e}^{-(\theta+r) T}}{\theta+r}\right)\right.\right. \\
& \left.\left.+c I_{p}\left(\frac{1-\mathrm{e}^{-r(N-M)}}{r}\right)\right]+\mathrm{e}^{\theta T}(a+b T)\left(h+\theta c+c I_{p}\right) \mathrm{e}^{-(\theta+r) T}\right\} / T>0 \\
& \frac{\mathrm{d} T C_{31}}{\mathrm{~d} T}=\left\{\mathrm{e}^{\theta T}(a+b T)\left[(h+\theta c)\left(\frac{1-\mathrm{e}^{-(\theta+r) T}}{\theta+r}\right)+c I_{p}\left(\frac{1-\mathrm{e}^{-(\theta+r)(T+N-M)}}{\theta+r}\right)\right]\right. \\
& \left.+c I_{p} \mathrm{e}^{-(\theta+r)(T+N-M)} \int_{T+N-M}^{T} \mathrm{e}^{\theta t} f(t) \mathrm{d} t-T C_{31}\right\} / T=0 \\
& \left.\frac{\mathrm{d}^{2} T C_{31}}{\mathrm{~d} T^{2}}\right|_{\frac{\mathrm{d} T C_{31}}{\mathrm{~d} T}=0} \\
& =\left\{\mathrm{e}^{\theta T}[\theta(a+b T)+b]\left[(h+\theta c)\left(\frac{1-\mathrm{e}^{-(\theta+r) T}}{\theta+r}\right)+c I_{p}\left(\frac{1-\mathrm{e}^{-(\theta+r)(T+N-M)}}{\theta+r}\right)\right]\right. \\
& +\mathrm{e}^{\theta T}(a+b T)\left[(h+\theta c) \mathrm{e}^{-(\theta+r) T}+c I_{p} \mathrm{e}^{-(\theta+r)(T+N-M)}\right]+c I_{p} \mathrm{e}^{-(\theta+r)(T+N-M)} \\
& \left.\times\left[\mathrm{e}^{\theta T} f(T)-\mathrm{e}^{\theta(T+N-M)} f(T+N-M)-(\theta+r) \int_{T+N-M}^{T} \mathrm{e}^{\theta t} f(t) \mathrm{d} t\right]\right\} / T>0
\end{aligned}
$$




$$
\begin{aligned}
& \frac{\mathrm{d} T C_{41}}{\mathrm{~d} T}=\left\{\mathrm{e}^{\theta T}(a+b T)(h+\theta c)\left(\frac{1-\mathrm{e}^{-(\theta+r) T}}{\theta+r}\right)\right. \\
& -p I_{e}\left[\left(\mathrm{e}^{-r T}-\mathrm{e}^{-r(M-T-N)}\right)\left(a T+\frac{b T^{2}}{2}\right)\right. \\
& \left.\left.+\frac{1-\mathrm{e}^{-r(M-T-N)}}{r}(a+b T)\right]-T C_{41}\right\} / T=0 \\
& \left.\frac{\mathrm{d}^{2} T C_{41}}{\mathrm{~d} T^{2}}\right|_{\frac{\mathrm{d} T C_{41}}{\mathrm{~d} T}=0} \\
& =\left\{\mathrm{e}^{\theta T}[\theta(a+b T)+b](h+\theta c)\left(\frac{1-\mathrm{e}^{-(\theta+r) T}}{\theta+r}\right)\right. \\
& +\mathrm{e}^{\theta T}(a+b T)(h+\theta c) \mathrm{e}^{-(\theta+r) T}+p I_{e}\left[r\left(\mathrm{e}^{-r T}+\mathrm{e}^{-r(M-T-N)}\right)\left(a T+\frac{b T^{2}}{2}\right)\right. \\
& \left.\left.-(a+b T)\left(\mathrm{e}^{-r T}-2 \mathrm{e}^{-r(M-T-N)}\right)-b\left(\frac{1-\mathrm{e}^{-r(M-T-N)}}{r}\right)\right]\right\} / T>0
\end{aligned}
$$

It is not easily to find the closed-form of $T$ from (22), (24), (26) and (28). However, we can use numerical method to find the solution. From (23), (25), (27) and (29), we know that the solution minimizes the total relevant cost function. By ensuring the solution satisfies the condition in each case, the following theoretical result is obtained.

Theorem 1. For the order quantity is not greater than the capacity of ownwarehouse (i.e., $Q \leq W$ )

a) As $Q<Q_{d}$, if $T_{11}<T_{d}$, then $T^{*}=T_{11}$.

b) As $Q \geq Q_{d}, \quad 0<M<N$, if $T_{21} \geq T_{d}$, then $T^{*}=T_{21}$.

c) As $Q \geq Q_{d}, \quad 0<N \leq M$, if $T_{31} \geq M-N$, then $T^{*}=T_{31}$.

d) As $Q \geq Q_{d}, 0<N \leq M$, if $T_{41}<M-N$, then $T^{*}=T_{41}$.

\subsection{The Case of Order Quantity Is Greater than the Capacity of Own-Warehouse (i.e., $Q>W$ )}

In this sub-section, we discuss each case shown in Section 3 as the order quantity is greater than the capacity of own-warehouse. From (5), we know that

$$
\frac{\mathrm{d} T_{a}}{\mathrm{~d} T}=\mathrm{e}^{\theta\left(T-T_{a}\right)} f(T) / f\left(T_{a}\right) .
$$

Similarly, to minimize the present value of the total relevant cost, it is necessary to calculate the first and second order derivatives of $T C_{i 2}(T), i=1,2,3,4$, with respect to $T$, and let $\mathrm{d} T C_{i 2}(T) / \mathrm{d} T=0$, We then obtain the following results.

$$
\begin{aligned}
\frac{\mathrm{d} T C_{12}}{\mathrm{~d} T}= & \left\{\mathrm { e } ^ { \theta T } ( a + b T ) \left[\left(h+\theta c+c I_{p}\right)\left(\frac{1-\mathrm{e}^{-(\theta+r) T}}{\theta+r}\right)+(k-h)\left(\frac{1-\mathrm{e}^{-(\theta+r) T_{a}}}{\theta+r}\right)\right.\right. \\
& \left.\left.-k \frac{\mathrm{e}^{-(\theta+r) T_{a}} W}{f\left(T_{a}\right)}+c I_{p}\left(\frac{1-\mathrm{e}^{-r N}}{r}\right)\right]-T C_{12}\right\} / T=0
\end{aligned}
$$




$$
\begin{aligned}
& \left.\frac{\mathrm{d}^{2} T C_{12}}{\mathrm{~d} T^{2}}\right|_{\frac{\mathrm{d} T C_{12}}{\mathrm{~d} T}=0} \\
& =\left\{\mathrm { e } ^ { \theta T } [ \theta ( a + b T ) + b ] \left[\left(h+\theta c+c I_{p}\right)\left(\frac{1-\mathrm{e}^{-(\theta+r) T}}{\theta+r}\right)\right.\right. \\
& \left.+(k-h)\left(\frac{1-\mathrm{e}^{-(\theta+r) T_{a}}}{\theta+r}\right)-k \frac{\mathrm{e}^{-(\theta+r) T_{a}} W}{f\left(T_{a}\right)}+c I_{p}\left(\frac{1-\mathrm{e}^{-r N}}{r}\right)\right] \\
& +\mathrm{e}^{\theta T}(a+b T)\left[\left(h+\theta c+c I_{p}\right) \mathrm{e}^{-(\theta+r) T}+(k-h) \mathrm{e}^{-(\theta+r) T_{a}} \frac{\mathrm{d} T_{a}}{\mathrm{~d} T}\right. \\
& \left.\left.+k \frac{\mathrm{e}^{-(\theta+r) T_{a}} W}{\left[f\left(T_{a}\right)\right]^{2}}\left((\theta+r) f\left(T_{a}\right)+f^{\prime}\left(T_{a}\right)\right) \frac{\mathrm{d} T_{a}}{\mathrm{~d} T}\right]\right\} / T>0 \\
& \frac{\mathrm{d} T C_{22}}{\mathrm{~d} T}=\left\{\mathrm { e } ^ { \theta T } ( a + b T ) \left[\left(h+\theta c+c I_{p}\right)\left(\frac{1-\mathrm{e}^{-(\theta+r) T}}{\theta+r}\right)+(k-h)\left(\frac{1-\mathrm{e}^{-(\theta+r) T_{a}}}{\theta+r}\right)\right.\right. \\
& \left.\left.-k \frac{\mathrm{e}^{-(\theta+r) T_{a}} W}{f\left(T_{a}\right)}+c I_{p}\left(\frac{1-\mathrm{e}^{-r(N-M)}}{r}\right)\right]-T C_{22}\right\} / T=0 \\
& \left.\frac{\mathrm{d}^{2} T C_{22}}{\mathrm{~d} T^{2}}\right|_{\frac{\mathrm{d} T C_{22}}{\mathrm{~d} T}=0} \\
& =\left\{\mathrm { e } ^ { \theta T } [ \theta ( a + b T ) + b ] \left[\left(h+\theta c+c I_{p}\right)\left(\frac{1-\mathrm{e}^{-(\theta+r) T}}{\theta+r}\right)\right.\right. \\
& \left.+(k-h)\left(\frac{1-\mathrm{e}^{-(\theta+r) T_{a}}}{\theta+r}\right)-k \frac{\mathrm{e}^{-(\theta+r) T_{a}} W}{f\left(T_{a}\right)}+c I_{p}\left(\frac{1-\mathrm{e}^{-r(N-M)}}{r}\right)\right] \\
& +\mathrm{e}^{\theta T}(a+b T)\left[\left(h+\theta c+c I_{p}\right) \mathrm{e}^{-(\theta+r) T}+(k-h) \mathrm{e}^{-(\theta+r) T_{a}} \frac{\mathrm{d} T_{a}}{\mathrm{~d} T}\right. \\
& \left.\left.+k \frac{\mathrm{e}^{-(\theta+r) T_{a}} W}{\left[f\left(T_{a}\right)\right]^{2}}\left((\theta+r) f\left(T_{a}\right)+f^{\prime}\left(T_{a}\right)\right) \frac{\mathrm{d} T_{a}}{\mathrm{~d} T}\right]\right\} / T>0 \\
& \frac{\mathrm{d} T C_{32}}{\mathrm{~d} T}=\left\{\mathrm { e } ^ { \theta T } ( a + b T ) \left[(h+\theta c)\left(\frac{1-\mathrm{e}^{-(\theta+r) T}}{\theta+r}\right)+c I_{p}\left(\frac{1-\mathrm{e}^{-(\theta+r)(T+N-M)}}{\theta+r}\right)\right.\right. \\
& \left.+(k-h)\left(\frac{1-\mathrm{e}^{-(\theta+r) T_{a}}}{\theta+r}\right)-k \frac{\mathrm{e}^{-(\theta+r) T_{a}} W}{f\left(T_{a}\right)}\right] \\
& \left.+c I_{p} \mathrm{e}^{-(\theta+r)(T+N-M)} \int_{T+N-M}^{T} \mathrm{e}^{\theta t} f(t) \mathrm{d} t-T C_{32}\right\} / T=0 \\
& \left.\frac{\mathrm{d}^{2} T C_{32}}{\mathrm{~d} T^{2}}\right|_{\frac{\mathrm{d} T C_{32}}{\mathrm{~d} T}=0} \\
& =\left\{\mathrm { e } ^ { \theta T } [ \theta ( a + b T ) + b ] \left[(h+\theta c)\left(\frac{1-\mathrm{e}^{-(\theta+r) T}}{\theta+r}\right)\right.\right. \\
& \left.+c I_{p}\left(\frac{1-\mathrm{e}^{-(\theta+r)(T+N-M)}}{\theta+r}\right)+(k-h)\left(\frac{1-\mathrm{e}^{-(\theta+r) T_{a}}}{\theta+r}\right)-k \frac{\mathrm{e}^{-(\theta+r) T_{a}} W}{f\left(T_{a}\right)}\right]
\end{aligned}
$$




$$
\begin{aligned}
& +\mathrm{e}^{\theta T}(a+b T)\left[(h+\theta c) \mathrm{e}^{-(\theta+r) T}+c I_{p} \mathrm{e}^{-(\theta+r)(T+N-M)}+(k-h) \mathrm{e}^{-(\theta+r) T_{a}} \frac{\mathrm{d} T_{a}}{\mathrm{~d} T}\right. \\
& \left.+k \frac{\mathrm{e}^{-(\theta+r) T_{a}} W}{\left[f\left(T_{a}\right)\right]^{2}}\left((\theta+r) f\left(T_{a}\right)+f^{\prime}\left(T_{a}\right)\right) \frac{\mathrm{d} T_{a}}{\mathrm{~d} T}\right]+c I_{p} \mathrm{e}^{-(\theta+r)(T+N-M)} \\
& \left.\times\left[\mathrm{e}^{\theta T} f(T)-\mathrm{e}^{\theta(T+N-M)} f(T+N-M)-(\theta+r) \int_{T+N-M}^{T} \mathrm{e}^{\theta t} f(t) \mathrm{d} t\right]\right\} / T>0 \\
& \frac{\mathrm{d} T C_{42}}{\mathrm{~d} T}=\left\{\mathrm { e } ^ { \theta T } ( a + b T ) \left[(h+\theta c)\left(\frac{1-\mathrm{e}^{-(\theta+r) T}}{\theta+r}\right)+(k-h)\left(\frac{1-\mathrm{e}^{-(\theta+r) T_{a}}}{\theta+r}\right)\right.\right. \\
& \left.-k \frac{\mathrm{e}^{-(\theta+r) T_{a}} W}{f\left(T_{a}\right)}\right]-p I_{e}\left[\left(\mathrm{e}^{-r T}-\mathrm{e}^{-r(M-T-N)}\right)\left(a T+\frac{b T^{2}}{2}\right)\right. \\
& \left.\left.+\frac{1-\mathrm{e}^{-r(M-T-N)}}{r}(a+b T)\right]-T C_{42}\right\} / T=0 \\
& \left.\frac{\mathrm{d}^{2} T C_{42}}{\mathrm{~d} T^{2}}\right|_{\frac{\mathrm{d} T C_{42}}{\mathrm{~d} T}=0} \\
& =\left\{\mathrm { e } ^ { \theta T } [ \theta ( a + b T ) + b ] \left[(h+\theta c)\left(\frac{1-\mathrm{e}^{-(\theta+r) T}}{\theta+r}\right)\right.\right. \\
& \left.+(k-h)\left(\frac{1-\mathrm{e}^{-(\theta+r) T_{a}}}{\theta+r}\right)-k \frac{\mathrm{e}^{-(\theta+r) T_{a}} W}{f\left(T_{a}\right)}\right] \\
& +\mathrm{e}^{\theta T}(a+b T)\left[(h+\theta c) \mathrm{e}^{-(\theta+r) T}+(k-h) \mathrm{e}^{-(\theta+r) T_{a}} \frac{\mathrm{d} T_{a}}{\mathrm{~d} T}\right. \\
& \left.+k \frac{\mathrm{e}^{-(\theta+r) T_{a}} W}{\left[f\left(T_{a}\right)\right]^{2}}\left((\theta+r) f\left(T_{a}\right)+f^{\prime}\left(T_{a}\right)\right) \frac{\mathrm{d} T_{a}}{\mathrm{~d} T}\right] \\
& +p I_{e}\left[r\left(\mathrm{e}^{-r T}-\mathrm{e}^{-r(M-T-N)}\right)\left(a T+\frac{b T^{2}}{2}\right)\right. \\
& \left.\left.-(a+b T)\left(\mathrm{e}^{-r T}-2 \mathrm{e}^{-r(M-T-N)}\right)-b\left(\frac{1-\mathrm{e}^{-r(M-T-N)}}{r}\right)\right]\right\} / T>0
\end{aligned}
$$

Similarly, it is also not easily to find the closed-form of $T$ from (31), (33), (35) and (37). However, we can use numerical method to find the solution. From (32), (34), (36) and (38), we know that the solution minimizes the total relevant cost function. By ensuring the solution satisfies the condition in each case, the following theoretical result is obtained.

Theorem 2. For the order quantity is greater than the capacity of own-warehouse (i.e., $Q>W$ )
a) As $Q<Q_{d}$, if $T_{12}<T_{d}$, then $T^{*}=T_{12}$.
b) As $Q \geq Q_{d}, \quad 0<M<N$, if $T_{22} \geq T_{d}$, then $T^{*}=T_{22}$.
c) As $Q \geq Q_{d}, \quad 0<N \leq M$, if $T_{32} \geq M-N$, then $T^{*}=T_{32}$.
d) As $Q \geq Q_{d}, \quad 0<N \leq M$, if $T_{42}<M-N$, then $T^{*}=T_{42}$. 
Summarizing the above arguments, we establish the algorithm to find the optimal solution, which is shown in Appendix A.

\section{Numerical Examples}

Let the demand rate $f(t)=200+150 t$ per year, $A=\$ 10$ per order, $h=$ $\$ 0.50 /$ unit/year, $k=\$ 0.60 /$ unit/year, $c=\$ 0.50 /$ unit, $p=\$ 1.00 /$ unit, $\theta=0.06, r$ $=0.06, I_{p}=0.06 /$ year, and $I_{e}=0.05 /$ year.

\section{1. $M<N$}

Let $M=1 / 12$ years, and $N=1 / 6$ years.

(I) Let $W=200$ units.

Example 1.1. Let $Q_{d}=150$ units. By (4), we have $T_{d}=0.60052$ years and by Appendix A, we have

$$
\begin{gathered}
T_{11}=0.36120, T_{12}=1.02268, T_{21}=0.36163, T_{22}=1.02320 \\
Q_{11}=82.95518, Q_{12}=292.66497, Q_{21}=83.06709, Q_{22}=292.86136
\end{gathered}
$$

and $T C_{11}\left(T_{11}\right)=52.70930, T C_{12}\left(T_{12}\right)=\infty, T C_{21}\left(T_{21}\right)=\infty$, $T C_{22}\left(T_{22}\right)=52.77053$. Thus, by Theorem 1(a), we know that the optimal solution is $T^{*}=T_{11}=0.36120$ years, and then $T C\left(T^{*}\right)=\min \{52.70930, \infty, \infty, 52.77053\}=52.70930=T C_{11}\left(T_{11}\right)$ and $Q^{*}=Q_{11}=82.95518$ units.

Example 1.2. Let $Q_{d}=50$ units. By (4), we have $T_{d}=0.22864$ years and by Appendix A, we have

$$
\begin{gathered}
T_{11}=0.36120, T_{12}=1.02268, T_{21}=0.36163, T_{22}=1.02320 \\
Q_{11}=82.95518, Q_{12}=292.66497, Q_{21}=83.06709, Q_{22}=292.86136
\end{gathered}
$$

and $T C_{11}\left(T_{11}\right)=\infty, T C_{12}\left(T_{12}\right)=\infty, T C_{21}\left(T_{21}\right)=52.13938$, $T C_{22}\left(T_{22}\right)=52.77053$. Thus, by Theorem 1(b), we know that the optimal solution is $T^{*}=T_{21}=0.36163$ years, and then $T C\left(T^{*}\right)=\min \{\infty, \infty, 52.13938,52.77053\}=52.13938=T C_{21}\left(T_{21}\right)$ and $Q^{*}=Q_{21}=83.06709$ units.

(II) Let $W=100$ units.

Example 1.3. Let $Q_{d}=200$ units. By (4), we have $T_{d}=0.75946$ years and by Appendix A, we have

$$
\begin{gathered}
T_{11}=0.36120, T_{12}=0.63118, T_{21}=0.36163, T_{22}=0.63164 \\
Q_{11}=82.95518, Q_{12}=159.30040, Q_{21}=83.06709, Q_{22}=159.44214
\end{gathered}
$$

and $T C_{11}\left(T_{11}\right)=52.70930, T C_{12}\left(T_{12}\right)=39.68433, T C_{21}\left(T_{21}\right)=\infty$, $T C_{22}\left(T_{22}\right)=\infty$. Thus, by Theorem $2(\mathrm{a})$, we know that the optimal solution is $T^{*}=T_{12}=0.63118$ years, and then $T C\left(T^{*}\right)=\min \{52.70930,39.68433, \infty, \infty\}=39.68433=T C_{12}\left(T_{12}\right)$ and $Q^{*}=Q_{12}=159.30040$ units.

Example 1.4. Let $Q_{d}=100$ units. By (4), we have $T_{d}=0.42547$ years and by Appendix A, we have 


$$
\begin{gathered}
T_{11}=0.36120, T_{12}=0.63118, T_{21}=0.36163, T_{22}=0.63164 \\
Q_{11}=82.95518, Q_{12}=159.30040, Q_{21}=83.06709, Q_{22}=159.44214
\end{gathered}
$$

and $T C_{11}\left(T_{11}\right)=52.70930, T C_{12}\left(T_{12}\right)=\infty, T C_{21}\left(T_{21}\right)=\infty$, $T C_{22}\left(T_{22}\right)=39.05803$. Thus, by Theorem 2(b), we know that the optimal solution is $T^{*}=T_{22}=0.63164$ years, and then $T C\left(T^{*}\right)=\min \{52.70930, \infty, \infty, 39.05803\}=39.05803=T C_{22}\left(T_{22}\right)$ and $Q^{*}=Q_{22}=159.44214$ units.

\section{2. $M \geq N$}

In this subsection, let $Q_{d}=50$ units. By (4), we have $T_{d}=0.22864$ years.

(I) Let $N=1 / 12$ years, $M=1 / 6$ years. (where $M-N=0.0833$ years)

Example 2.1. Let $W=200$ units. By Appendix A, we have

$$
\begin{gathered}
T_{31}=0.36117, T_{32}=1.02360, T_{41}=0.35641, T_{42}=1.01153 \\
Q_{31}=82.94731, Q_{32}=293.01007, Q_{41}=81.71258, Q_{42}=288.48813
\end{gathered}
$$

and $T C_{31}\left(T_{31}\right)=51.39797, T C_{32}\left(T_{32}\right)=51.98859, T C_{41}\left(T_{41}\right)=\infty$, $T C_{42}\left(T_{42}\right)=\infty$. Thus, by Theorem $1(\mathrm{c})$, we know that the optimal solution is $T^{*}=T_{31}=0.36117$ years, and then $T C\left(T^{*}\right)=\min \{51.39797,51.98859, \infty, \infty\}=51.39797=T C_{31}\left(T_{31}\right)$ and $Q^{*}=Q_{31}=82.94731$ units.

Example 2.2. Let $W=100$ units. By Appendix A, we have

$$
\begin{gathered}
T_{31}=0.36117, T_{32}=0.63180, T_{41}=0.35641, T_{42}=0.62414 \\
Q_{31}=82.94731, Q_{32}=159.49012, Q_{41}=81.71258, Q_{42}=157.14949
\end{gathered}
$$

and $T C_{31}\left(T_{31}\right)=51.39797, T C_{32}\left(T_{32}\right)=38.32624, T C_{41}\left(T_{41}\right)=\infty$, $T C_{42}\left(T_{42}\right)=\infty$. Thus, by Theorem $2(\mathrm{c})$, we know that the optimal solution is $T^{*}=T_{32}=0.63180$ years, and then $T C\left(T^{*}\right)=\min \{51.39797,38.32624, \infty, \infty\}=38.32624=T C_{32}\left(T_{32}\right)$ and $Q^{*}=Q_{32}=159.49012$ units.

(II) Let $M=3 / 4$ years, $N=1 / 12$ years. (where $M-N=0.6667$ years)

Example 2.3. Let $W=200$ units. By Appendix A, we have

$$
\begin{gathered}
T_{31}=0.29507, T_{32}=1.01509, T_{41}=0.36166, T_{42}=1.01799 \\
Q_{31}=66.14744, Q_{32}=289.82066, Q_{41}=83.07556, Q_{42}=290.90430
\end{gathered}
$$

and $T C_{31}\left(T_{31}\right)=\infty, T C_{32}\left(T_{32}\right)=47.53500, T C_{41}\left(T_{41}\right)=44.90899$, $T C_{42}\left(T_{42}\right)=\infty$. Thus, by Theorem $1(\mathrm{~d})$, we know that the optimal solution is $T^{*}=T_{41}=0.36166$ years, and then $T C\left(T^{*}\right)=\min \{\infty, 47.53500,44.90989, \infty\}=44.90989=T C_{41}\left(T_{41}\right)$ and $Q^{*}=Q_{41}=83.07556$ units.

Example 2.4. Let $W=100$ units. By Appendix A, we have

$$
\begin{gathered}
T_{31}=0.29507, T_{32}=0.61127, T_{41}=0.36166, T_{42}=0.62982 \\
Q_{31}=66.14744, Q_{32}=153.24078, Q_{41}=83.07556, Q_{42}=158.88557
\end{gathered}
$$

and $T C_{31}\left(T_{31}\right)=\infty, T C_{32}\left(T_{32}\right)=\infty, T C_{41}\left(T_{41}\right)=44.90989$, 
$T C_{42}\left(T_{42}\right)=31.93704$. Thus, by Theorem 2(d), we know that the optimal solution is $T^{*}=T_{42}=0.62982$ years, and then

$T C\left(T^{*}\right)=\min \{\infty, \infty, 44.90989,31.93704\}=31.93704=T C_{42}\left(T_{42}\right)$ and $Q^{*}=Q_{42}=158.88557$ units.

Summarizing the above numerical results, we have the following Table 1 and Table 2.

Table 1. Summary on optimal solutions for Examples 1.1-1.4.

\begin{tabular}{|c|c|c|c|c|}
\hline \multicolumn{5}{|c|}{$M<N$} \\
\hline Example & 1.1 & 1.2 & 1.3 & 1.4 \\
\hline$M$ & \multicolumn{4}{|c|}{$1 / 12$} \\
\hline$N$ & \multicolumn{4}{|c|}{$1 / 6$} \\
\hline$W$ & \multicolumn{2}{|c|}{200} & \multicolumn{2}{|c|}{100} \\
\hline$Q_{d}$ & 150 & 50 & 200 & 100 \\
\hline$T_{d}$ & 0.60052 & 0.22864 & 0.75946 & 0.42547 \\
\hline$T^{*}$ & 0.36120 & 0.36163 & 0.63118 & 0.63164 \\
\hline$Q^{*}$ & 82.9552 & 83.0671 & 159.3004 & 159.4421 \\
\hline$T C\left(T^{*}\right)$ & 52.7093 & 52.1394 & 39.6843 & 39.0580 \\
\hline \multirow[t]{3}{*}{ Case } & 3.1 & 3.2 .1 & 3.1 & 3.2 .1 \\
\hline & $Q^{*} \leq W$ & $Q^{*} \leq W$ & $Q^{*}>W$ & $Q^{*}>W$ \\
\hline & $Q^{*}<Q_{d}$ & $Q^{*} \geq Q_{d}$ & $Q^{*}<Q_{d}$ & $Q^{*} \geq Q_{d}$ \\
\hline Theorem & 1(a) & 1(b) & 2(a) & $2(b)$ \\
\hline Warehouse No. & $1 W$ & $1 W$ & $2 W$ & $2 W$ \\
\hline
\end{tabular}

Table 2. Summary on optimal solutions for Examples 2.1-2.4.

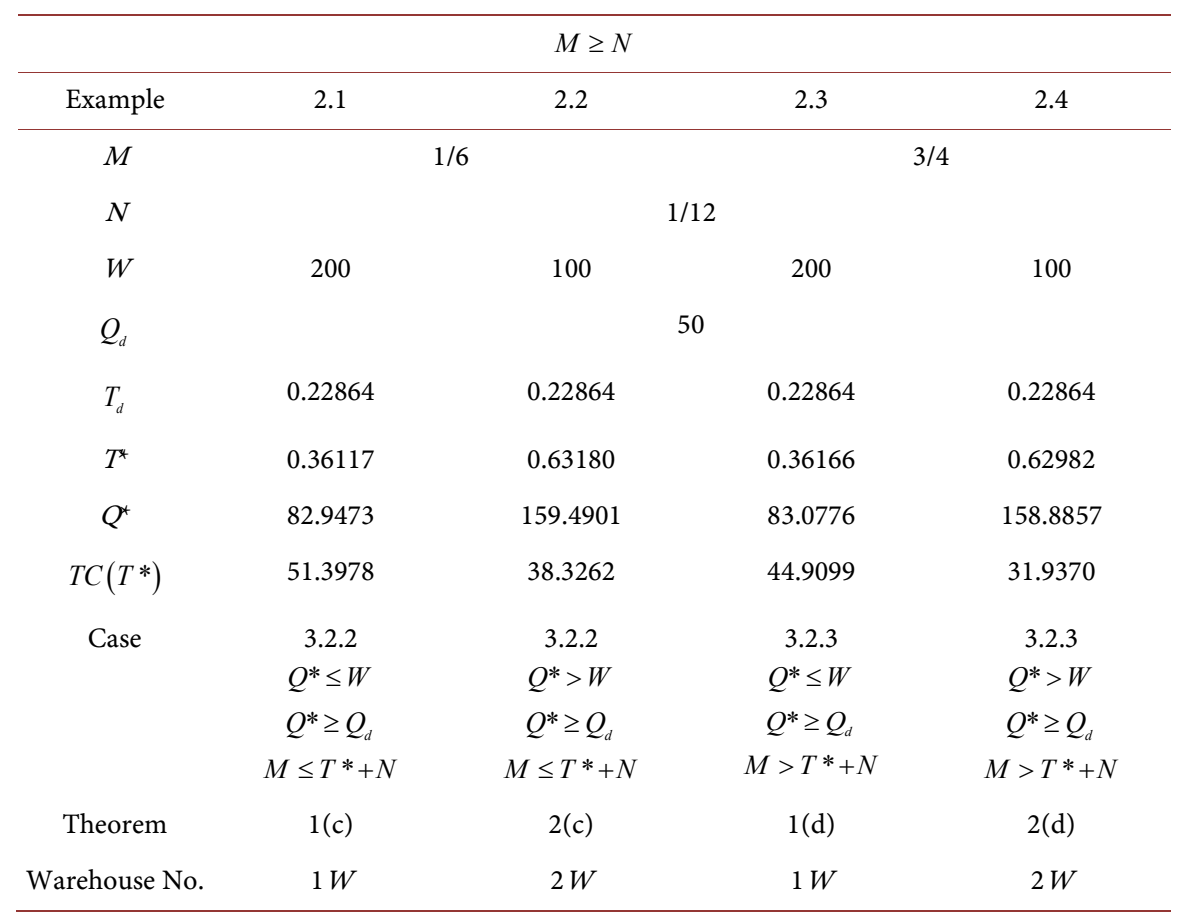


From Table 1 and Table 2, some managerial insights can be obtained.

1) As the predetermined order quantity $Q_{d}$ increases, then the retailer's total relevant cost $T C\left(T^{*}\right)$ increases, the optimal replenishment time $T^{*}$ and the optimal order quantity $Q^{*}$ decrease. It reveals that if predetermined order quantity is large, then it is not beneficial for the retailer.

2) As the capacity of own-warehouse $W$ increases, the optimal replenishment time $T^{*}$ and the optimal order quantity $Q^{*}$ decrease. It reveals that adopt one-warehouse is advantageous for the retailer, since need not to rent a warehouse, but the optimal retailer's total relevant cost is higher.

3) As the upstream trade credit period $M$ increases, the optimal retailer's total relevant cost $T C\left(T^{*}\right)$ decreases, the optimal replenishment time $T^{*}$ and the optimal order quantity $Q^{*}$ increase. It reveals that the longer upstream trade credit period, the less the retailer's total relevant cost is.

4) As the downstream trade credit period $N$ increases, then the retailer's total relevant cost $T C\left(T^{*}\right)$ increases, since the retailer need to pay more interest than earned. Further, the optimal replenishment time $T^{*}$ and the optimal order quantity $Q^{*}$ decrease.

5) As the difference $M-N$ increases, then the retailer's total relevant cost $T C\left(T^{*}\right)$ decreases. It reveals that the longer the upstream trade credit period and the shorter the downstream trade credit period will cause the retailer's total relevant cost to be less. It will be more profitable for the retailer. Further, the optimal replenishment time $T^{*}$ and the optimal order quantity $Q^{*}$ decrease in the case of $Q>W$, whereas increase in the case of $Q \leq W$.

\section{Conclusions}

In this paper, an inventory model for deteriorating items with limited storage capacity in a supply chain is developed. The supplier offers a permissible delay in payment linked to order quantity, in the meanwhile, the retailer also provides a downstream trade credit period to its customers. The demand rate is linearly increasing with time and the deterioration rate is constant. Simultaneously, the discounted cash flow analysis is also taken into account. The results reveal that 1 ) as the optimal order quantity is less than the predetermined order quantity $\left(Q^{*}<Q_{d}\right)$ and the optimal order quantity is not greater than the capacity of own-warehouse $\left(Q^{*} \leq W\right)$ will cause more retailer's total relevant cost than other cases, since there is no upstream trade credit period allowed, the retailer need to pay more interest than earned.. This is the worst one. 2) As the optimal order quantity is not less than the predetermined order quantity $\left(Q^{*} \geq Q_{d}\right)$, the optimal order quantity is greater than the capacity of own-warehouse $\left(Q^{*}>W\right)$ and $N<M, M>T^{*}+N$ will cause less retailer's total relevant cost than the others, since the retailer can earn more interest than paid. It's more profitable for the retailer in such case. 3) The retailer's total relevant cost increase as any one of the parameter values $W, Q_{d}, N$ increases, while decreases as $M$ increases. Thus, if the upstream trade credit period is longer, the downstream trade credit 
period is shorter, and the predetermined order quantity is less, then the retailer's total relevant cost will be less, it's more beneficial for the retailer.

The model can be extended in several ways, for example, extend the model to allow for shortages and partial backlogging or partial trade credit. Also, we can add the pricing, quality strategies into consideration.

\section{Conflicts of Interest}

The author declares no conflicts of interest regarding the publication of this paper.

\section{References}

[1] Goyal, S.K. (1985) Economic Order Quantity under Conditions of Permissible Delay in Payments. Journal of the Operational Research Society, 36, 335-338. https://doi.org/10.1057/jors.1985.56

[2] Shah, N.H. (1993) Probabilistic Time-Scheduling Model for an Exponentially Decaying Inventory When Delay in Payments Is Permissible. International Journal of Production Economics, 32, 77-82. https://doi.org/10.1016/0925-5273(93)90009-A

[3] Aggarwal, S.P. and Jaggi, C.K. (1995) Ordering Policies of Deteriorating Items under Permissible Delay in Payments. Journal of the Operational Research Society, 46, 658-662. https://doi.org/10.1057/jors.1995.90

[4] Jamal, A.M.M., Sarker, B.R. and Wang, S. (1997) An Ordering Policy for Deteriorating Items with Allowable Shortages and Permissible Delay in Payments. Journal of the Operational Research Society, 48, 826-833. https://doi.org/10.1057/palgrave.jors.2600428

[5] Hwang, H. and Shinn, S.W. (1997) Retailer's Pricing and Lot Sizing Policy for Exponentially Deteriorating Products under the Conditions of Permissible Delay in Payments. Computers \& Operations Research, 24, 539-547. https://doi.org/10.1016/S0305-0548(96)00069-X

[6] Chang, H.J. and Dye, C.Y. (2001) An Inventory Model for Deteriorating Items with Partial Backlogging and Permissible Delay in Payments. International Journal of Systems Science, 32, 345-352. https://doi.org/10.1080/002077201300029700

[7] Teng, J.T., Min, J. and Pan, Q.H. (2012) Economic Order Quantity Model with Trade Credit Financing for Non-Decreasing Demand. Omega, 40, 328-335. https://doi.org/10.1016/j.omega.2011.08.001

[8] Teng, J.T. (2002) On the Economic Order Quantity under Conditions of Permissible Delay in Payments. Journal of the Operational Research Society, 53, 915-918. https://doi.org/10.1057/palgrave.jors.2601410

[9] Teng, J.T., Chang, C.T., Chern, M.S. and Chan, Y.L. (2007) Retailer's Optimal Ordering Policies with Trade Credit Financing. International Journal of Systems Science, 38, 269-278. https://doi.org/10.1080/00207720601158060

[10] Hsieh, T.P., Chang, H.J., Dye, C.Y. and Weng, M.W. (2009) Optimal Lot Size under Trade Credit Financing When Demand and Deterioration Are Fluctuating with Time. International Journal of Information and Management Science, 20, 191-204.

[11] Huang, Y.F. (2003) Optimal Retailer's Ordering Policies in the EOQ Model under Trade Credit Financing. Journal of the Operational Research Society, 54, 1011-1015. https://doi.org/10.1057/palgrave.jors.2601588

[12] Ouyang, L.Y., Chang, C.T. and Teng, J.T. (2005) An EOQ Model for Deteriorating 
Items under Trade Credit. Journal of the Operational Research Society, 56, 719-726. https://doi.org/10.1057/palgrave.jors.2601881

[13] Teng, J.T. and Goyal, S.K. (2007) Optimal Ordering Policies for a Retailer in a Supply Chain with Up-Stream and Down-Stream Trade Credits. Journal of Operational Research Society, 58, 1252-1255. https://doi.org/10.1057/palgrave.jors.2602404

[14] Min, J., Zhou, Y.W. and Zhao, J. (2010) An Inventory Model for Deteriorating Items under Stock-Dependent Demand and Two Level Trade Credit. Applied Mathematical Modelling, 34, 3273-3285. https://doi.org/10.1016/j.apm.2010.02.019

[15] Rameswari, M. and Uthayakumar, R. (2018) An Integrated Inventory Model for Deteriorating Items with Price-Dependent Demand under Two-Level Trade Credit Policy. International Journal of Systems Science, Operation \& Logistics, 5, 253-267.

[16] Chang, C.T., Ouyang, L.Y. and Teng, J.T. (2003) An EOQ Model for Deteriorating Items under Supplier Credits Linked to Order Quantity. Applied Mathematical Modelling, 27, 983-996. https://doi.org/10.1016/S0307-904X(03)00131-8

[17] Chung, K.J. and Liao, J.J. (2004) Lot-Sizing Decisions under Trade Credit Depending on the Ordering Quantity. Computers \& Operations Research, 31, 909-928. https://doi.org/10.1016/S0305-0548(03)00043-1

[18] Jaggi, C.K., Goyal, S.K. and Goel, S.K. (2008) Retailer's Optimal Replenishment Decisions with Credit-Linked Demand under Permissible Delay in Payments. European Journal of Operational Research, 190, 130-135. https://doi.org/10.1016/j.ejor.2007.05.042

[19] Kreng, V.B. and Tan, S.J. (2010) The Optimal Replenishment Decision under Two Levels of Trade Credit Policy Depending on the Order Quantity. Expert Systems with Applications, 37, 5514-5522. https://doi.org/10.1016/j.eswa.2009.12.014

[20] Teng, J.T., Yang, H.L. and Chern, M.S. (2013) An Inventory Model for Deteriorating Demand under Two Levels of Trade Credit Linked to Order Quantity. Applied Mathematical Modelling, 37, 7624-7632. https://doi.org/10.1016/j.apm.2013.02.009

[21] Shah, N.H. and Cárdenas-Barrón, L.E. (2015) Retailer's Decision for Ordering and Credit Policies for Deteriorating Items When a Supplier Offers Order-Linked Credit or Cash Discount. Applied Mathematics and Computation, 259, 569-578. https://doi.org/10.1016/j.amc.2015.03.010

[22] Ting, P.S. (2015) Comments on the EOQ Model for Deteriorating Items with Conditional Trade Credit Linked to Order Quantity. European Journal of Operational Research, 246, 108-118. https://doi.org/10.1016/j.ejor.2015.04.046

[23] Chung, K.J. and Huang, T.S. (2006) The Optimal Cycle Time for Deteriorating Items with Limited Storage Capacity under Permissible Delay in Payments. AsiaPacific Journal of Operational Research, 23, 347-370. https://doi.org/10.1142/S0217595906000814

[24] Huang, Y.F. (2006) An Inventory Model under Two Levels of Trade Credit and Limited Storage Space without Derivatives. Applied Mathematical Modelling, 30, 418-436. https://doi.org/10.1016/j.apm.2005.05.009

[25] Chung, K.J. and Huang, T.S. (2007) The Optimal Retailer's Ordering Policies for Deteriorating Items with Limited Storage Capacity under Trade Credit Financing. International Journal of Production Economics, 106, 127-145. https://doi.org/10.1016/j.ijpe.2006.05.008

[26] Ouyang, L.Y., Wu, K.S. and Yang, C.T. (2007) An EOQ Model with Limited Storage Capacity under Trade Credits. Asia-Pacific Journal of Operational Research, 24, 575-592. https://doi.org/10.1142/S0217595907001371 
[27] Lin, F., Jia, T., Wu, F. and Yang, Z. (2019) Impacts of Two-Stage Deterioration on an Integrated Inventory Model under Trade Credit and Variable Capacity Utilization. European Journal of Operational Research, 272, 219-234. https://doi.org/10.1016/j.ejor.2018.06.022

[28] Chen, S.C. and Teng, J.T. (2015) Inventory and Credit Decisions for Time-Varying Deteriorating Items with Up-Stream and Down-Stream Trade Credit Financing by Discounted Cash Flow Analysis. European Journal of Operational Research, 243, 566-575. https://doi.org/10.1016/j.ejor.2014.12.007

[29] Wu, J., Al-khateeb, F.B., Teng, J.T. and Cárdenas-Barrón, L.E. (2016) Inventory Models for Deteriorating Items with Maximum Lifetime under Downstream Partial Trade Credits to Credit-Risk Customers by Discounted Cash-Flow Analysis. International Journal of Production Economics, 171, 105-115.

https://doi.org/10.1016/j.ijpe.2015.10.020

[30] Li, R., Chan, Y.L., Chang, C.T. and Cárdenas-Barrón, L.E. (2017) Pricing and Lot-Sizing Policies for Perishable Products with Advance-Cash-Credit Payments by a Discounted Cash-Flow Analysis. International Journal of Production Economics, 193, 578-589. https://doi.org/10.1016/j.ijpe.2017.08.020 


\section{Appendix A. Algorithm for Finding the Optimal Solution}

Step 0. Input parameter values.

Step 0.1. By (4), calculate $T_{d}$.

Step 0.2. Compare the values of $M$ and $N$. If $M<N$, then go to Step 1. Otherwise, go to Step 5.

Step 1. By (22), (24), (31),(33), calculate $T$, let it be $T_{11}, T_{21}, T_{12}, T_{22}$.

Step 2. By (3), for each $T_{i j}$, calculate $Q_{i j}, i=1,2, j=1,2$.

Step 3. Compare the values of $Q_{i j}, i=1,2, j=1,2$ and $W$.

Step 3.1. If $Q_{11}<Q_{d}$ and $Q_{11} \leq W$, then $T^{*}=T_{11}$, and calculate $T C_{11}\left(T^{*}\right)$. Otherwise, set $T C_{11}\left(T_{11}\right)=\infty$.

Step 3.2. If $Q_{12}<Q_{d}$ and $Q_{12}>W$, then $T^{*}=T_{12}$, and calculate $T C_{12}\left(T^{*}\right)$. Otherwise, set $T C_{12}\left(T_{12}\right)=\infty$.

Step 3.3. If $Q_{21} \geq Q_{d}$ and $Q_{21} \leq W$, then $T^{*}=T_{21}$ and calculate $T C_{21}\left(T^{*}\right)$, Otherwise, set $T C_{21}\left(T_{21}\right)=\infty$.

Step 3.4. If $Q_{22} \geq Q_{d}$ and $Q_{22}>W$, then $T^{*}=Q_{22}$, and calculate $T C_{22}\left(T^{*}\right)$. Otherwise, set $T C_{22}\left(T_{22}\right)=\infty$.

Step 4. Set $T C\left(T^{*}\right)=\min \left\{T C_{i j}\left(T_{i j}\right) \mid i=1,2, j=1,2\right\}$ then $T^{*}=T_{i j}$ is the optimal solution, for a certain $i, j$ and stop.

Step 5. By (26), (28), (35), (37), calculate $T$, let it be $T_{31}, T_{41}, T_{32}, T_{42}$.

Step 6. By (3), for each $T_{i j}$, calculate $Q_{i j}, i=3,4, j=1,2$.

Step 7. Compare the values of $Q_{i j}, i=3,4, j=1,2$.and $W$

Step 7.1. If $Q_{31} \geq Q_{d}, Q_{31} \leq W$ and $T_{31} \geq M-N$, then $T^{*}=T_{31}$ and calculate $T C_{31}\left(T^{*}\right)$. Otherwise, set $T C_{31}\left(T_{31}\right)=\infty$.

Step 7.2. If $Q_{32} \geq Q_{d}, Q_{32}>W$ and $T_{32} \geq M-N$, then $T^{*}=T_{32}$ and calculate $T C_{32}\left(T^{*}\right)$, Otherwise, set $T C_{32}\left(T_{32}\right)=\infty$.

Step 7.3. If $Q_{41} \geq Q_{d}, Q_{41} \leq W$ and $T_{41}<M-N$, then $T^{*}=T_{41}$ and calculate $T C_{41}\left(T^{*}\right)$. Otherwise, set $T C_{41}\left(T_{41}\right)=\infty$.

Step 7.4. If $Q_{42} \geq Q_{d}, Q_{42}>W$ and $T_{42}<M-N$, then $T^{*}=T_{42}$ and calculate $T C_{42}\left(T^{*}\right)$. Otherwise, set $T C_{42}\left(T_{42}\right)=\infty$.

Step 8. Set $T C\left(T^{*}\right)=\min \left\{T C_{i j}\left(T_{i j}\right) \mid i=3,4, j=1,2\right\}$ then $T^{*}=T_{i j}$ is the optimal solution, for a certain $i, j$ and stop. 